\title{
Effectiveness of the kinesiotaping in the patellofemoral pain syndrome
}

\author{
Ezel Günay' ${ }^{1}$, Selda Sarkkaya ${ }^{1}$, Şenay Özdolapp ${ }^{1}$, Çağatay Büyükuysal ${ }^{2}$ \\ ${ }^{1}$ Department of Physical and Rehabilitation Medicine, Bülent Ecevit University Medical School, Zonguldak, Turkey \\ ${ }^{2}$ Department of Biostatistics, Bülent Ecevit University Medical School, Zonguldak, Turkey
}

Received: June 2016 Accepted: December 2016

\begin{abstract}
Objectives: This study aims to evaluate the effect of kinesiotaping implementation on pain and functional status in patellofemoral pain syndrome (PFPS).

Patients and methods: Between January 2014 and July 2014, this prospective, single-center, randomized-controlled study included a total of 75 knees from 43 patients ( 20 males, 23 females; mean age $33.8 \pm 7.9$ years; range, 20 to 50 years). All patients were divided into three treatment groups: Group 1 ( 25 knees) were treated with kinesiotaping and exercise, Group 2 ( 25 knees) were treated with sham taping + and exercise, and Group 3 (25 knees) were treated with exercise alone. The Visual Analog Scale (VAS) was used to assess the pain severity. The Kujala Patellofemoral Scale (KPS) was used to determine the effect of the knee pain on the patients' daily living activities. All three groups were given the same exercise program during six weeks. Kinesiotaping was applied twice a week, 12 times in total during the treatment period of six weeks. The VAS and KPS assessments for all patients were made at baseline, then at the end of the treatment (week 6) and at week 12 the end of the $12^{\text {th }}$ week.

Results: There were no statistically significant differences between the three groups in terms of age, sex, height, weight, and Body Mass Index ( $>0.05$, for all). A statistically significant improvement was observed in all groups in terms of the mean VAS and KPS scores before the treatment, at week 6 , and at week 12 ( $\mathrm{p}<0.001$, for all). There was no statistically significant change in the mean changes of the VAS and KPS among the groups at week 6 and 12 .
\end{abstract}

Conclusion: Our study results suggest that the addition of the kinesiotaping application to the exercise treatment for PFPS seems to be ineffective on pain control and improved daily life activities.

Keywords: Exercise; kinesiotaping; patellofemoral pain.

Patellofemoral pain syndrome (PFPS) is a syndrome characterized by the pain in the anterior knee. ${ }^{[1,2]}$ It is the most frequent disease of the knee in early childhood. There are many etiological factors and there is no a certain algorithm in the treatment. ${ }^{[1,3,4]}$ Disorders in the extensor mechanism of the knee are considered as the most important factors for the PFAS..$^{[1,3,4]}$ Musculus vastus medialis obliquus (VMO) and vastus lateralis are the most important dynamic forces having an effect on patella at the last 30 degrees of the knee extension. During the extensional motion of the knee, VMO is contracted before musculus vastus lateralis which preactivates the medial force vectors, thus, preventing the lateral patellar dislocation. ${ }^{[4-6]}$ Delay in the VMO activity and decrease in the muscle strength cause a decrease in the medial patellar stability, a balance disorder in the force vector affecting the patella and lateral movement of the patella, and also an increase in the joint pressure on the lateral facet. Therefore, this causes PFPS by changing the patellofemoral contact area and contact pressure..$^{[1,4,7]}$

The goal of the treatment of PFPS is to recover the patellofemoral joint biomechanics and to increase the quadriceps muscle strength by decreasing the patellofemoral joint reaction and stress. ${ }^{[2,4,6,7]}$ Conservative methods are often used in the treatment of PFPS. However, there is no consensus on the most optimal treatment approach. Physiotherapy modalities, strengthening and stretching exercises for the muscles around the knee, balance-coordination

Corresponding author: Selda Sarıkaya, MD. Bülent Ecevit Üniversitesi Tıp Fakültesi Fiziksel Tıp ve Rehabilitasyon Anabilim Dalı, 67600 Zonguldak, Turkey. e-mail: seldaki@hotmail.com 
exercises, electromyography (EMG) biofeedback, patellar brace, patellar taping, and feet orthotics are the treatment methods in use currently. ${ }^{[3,8,9]}$ There are strong evidences demonstrating the effectiveness of the quadriceps exercises, although there is a limited number of evidences showing the effectiveness of the other treatment methods. ${ }^{[8]}$

In several studies on the effects of the kinesiotaping on different musculoskeletal disorders, kinesiological taping has been found to strengthen the muscles around the joints, increase the joint stability, ease the joint mobility, decrease the tension in the muscles, ligaments and tendons, and increase the proprioception..$^{[10-15]}$ In addition, there are controversial results of previous studies on the effectiveness of the kinesiotaping for PFPS. ${ }^{[3]}$ While some authors claim an increase in the muscle strength and proprioception, ${ }^{[16,17]}$ others suggest no changes in the muscle strength and proprioception, despite the alleviation in the pain ${ }^{[18-20]}$ and there are very few researches on the effect of the kinesiotaping for the daily living activities in the patients having PFPS. ${ }^{[18,21]}$

In the present study, we aimed to investigate the contribution of the kinesiotaping application to the exercise treatment in PFPS in terms of pain and daily living activities.

\section{PATIENTS AND METHODS}

This prospective, single-center, randomizedcontrolled, parallel-group study included a total of 75 knees of 43 patients ( 20 males, 23 females; mean age $33.8 \pm 7.9$ years; range 20 to 50 years) who were admitted to the Department of Physical Medicine and Rehabilitation for anterior knee pain and who were diagnosed with PFPS ${ }^{[22]}$ between January 2014 and July 2014. Inclusion criteria were as follows: being within the age range of 20 to 50 years, having no limitation in the range of motion of the knee joint, having anterior or retropatellar knee pain in at least two activities (i.e., going down the stairs, climbing up the stairs, squatting, running, jumping, sitting for a long time while the knees are at $90^{\circ}$ flexion), and having earlyonset anterior knee pain for at least the last six months. Exclusion criteria were as follows: history of knee trauma, prior knee operation (excluding arthroscopy), meniscopathy or lesion in the knee ligaments, previous effusion and arthritis of the knee, patellar subluxation or dislocation, limited range of motion of the ankle or the knee, and neuromuscular diseases (upper and lower motor neuron lesions).
The study was approved by the Local Ethics Committee (No: 2013-22-26/02). All patients were informed in detail about the study and a written informed consent was obtained from each patient. The study was conducted in accordance with the principles of the Declaration of Helsinki.

A total of 75 knees from 43 patients were divided into three treatment groups. The participants were randomly assigned following simple randomization procedures (computerized random numbers) to one of three treatment groups. Group 1 (25 knees) were treated with kinesiotaping and exercise, Group 2 (25 knees) were treated with sham taping + and exercise, and Group 3 ( 25 knees) were treated with exercise alone.

The Visual Analog Scale (VAS) was used to assess the pain severity. The patients were asked to mark their pain levels on a $100-\mathrm{mm}$ ruler $(0=$ no pain, $100=$ highest level pain).

The Kujala Patellofemoral Scale (KPS) was used to determine the effect of the knee pain on the patients' daily living activities. ${ }^{[23,24]}$ It is a 13 -item questionnaire through which difficulties and pains during an activity is assessed. Total score ranges from 0 to 100.100 refer to a normal, painless and fully functional knee, while 0 indicates serious knee pain and dysfunction.

The VAS and KPS assessments for all the patients were made at baseline, then at the end of the treatment (week 6) and at the end of week 12.

\section{Treatment protocols}

All three groups were given the same exercise program during six weeks. Taping was applied twice a week, 12 times in total during treatment period of six weeks.

Stretching (quadriceps, hamstring, gastrocnemius and iliotibial band) and strengthening (quadriceps, gluteus medius) exercises were applied during six weeks as two times a week (12 sessions) in the clinic by the supervision of a physiotherapist. The patients were informed and encouraged about the daily exercises at home on the other days. Exercises were done in three sets with 10 times repetition.

Kinesiotape applications were performed according to the method established by the Kinesio Taping Association International. ${ }^{[15]} 5 \mathrm{~cm}$ width Kinesio ${ }^{\circ}$ Tex tapes were used for taping. All the taping processes were performed by a specialist.

Kinesiotaping was applied to Group 1 with vastus medialis obliquus facilitation and patellar functional 


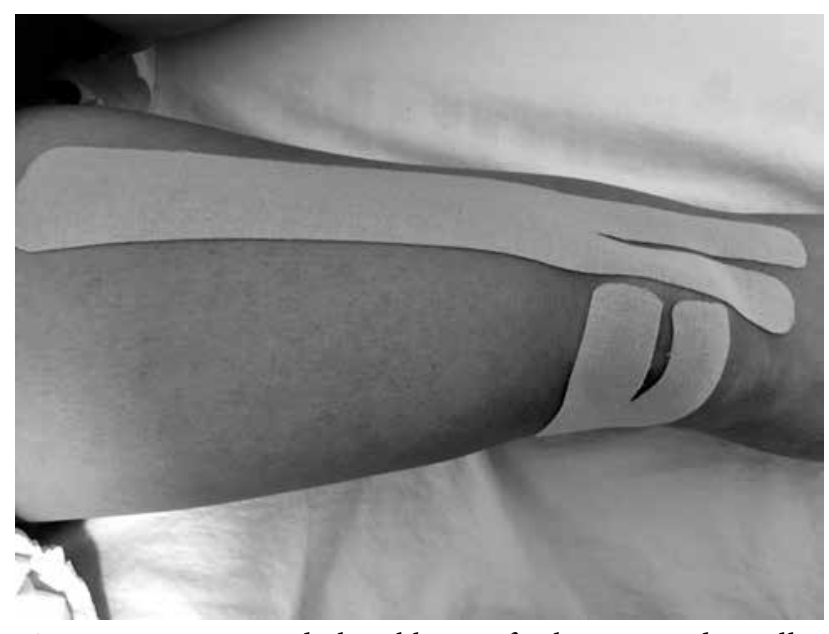

Figure 1. Vastus medialis obliquus facilitation and patellar kinesiotaping application (Group 1).

correction (Figure 1). ${ }^{[15]}$ In the VMO facilitation, the interval between the superior anterior iliac spine and patella midpoint, while the patients were supine position was measured. The length of the tape was taken as the half of this interval. A 2-inch I strip of Kinesio $^{\oplus}$ Tex Tape split to a Y. Tails of the Y strip prepared were considered as $1 / 2$ of the tape length. The first part of the tape, which is called "base", was applied without strain on the VMO body and lateral "Y" tail applied along the pes anserinus and ended on tibia, while on the knee extension. The patient was, then, asked to move his/her knee to full flexion. The medial "Y" tail was applied along the medial side of the patella and ended at the lower end of the patella. The rest excluding the first and last $5 \mathrm{~cm}$ of the tape was applied with 50\% tension (Figure 1).

For the patellar taping, the tape length was measured as starting from the capitulum fibulae and ending on the medial border of patella. Tails of the "Y" tape were prepared as one-third of the total length. The base part of the tape was applied starting from the capitulum fibulae and toward the medial.

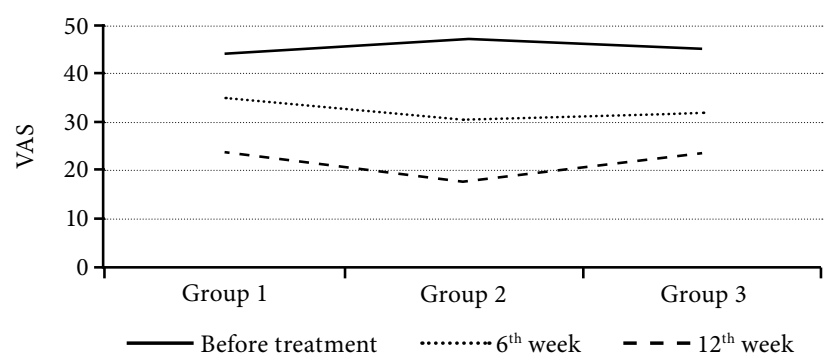

Figure 3. The changes in Visual Analog Scale (VAS) scores at week 6 and week 12 .

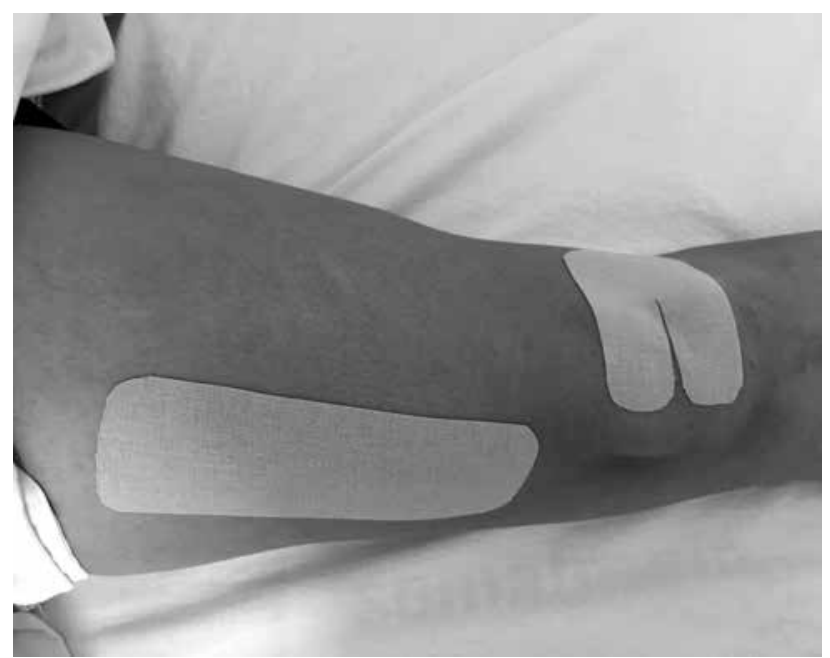

Figure 2. Sham kinesiotaping application (Group 2).

The knee was brought to full flexion for "Y" tails and the upper tail was applied in a way the upper to surround the upper patella and the lower tail to surround the lower patella. The rest excluding the first and the last $5 \mathrm{~cm}$ of the tape was applied with $75 \%$ tension (Figure 1).

Sham taping application was planned for the Group 2. The interval between the superior anterior iliac protrusion and patella midpoint was measured for VMO. The length of the tape was measured as one-third of this interval. The "I" shape tape was applied starting from the VMO midpoint and toward the patella (Figure 2).

For patella, the tape length was measured in a way to start from capitulum fibulae and ending patella midpoint. The "Y" tapes were prepared in a way to be one-third of the total length. The base of tape was applied starting from the capitulum fibula and toward the medial. The knee was brought to full flexion and

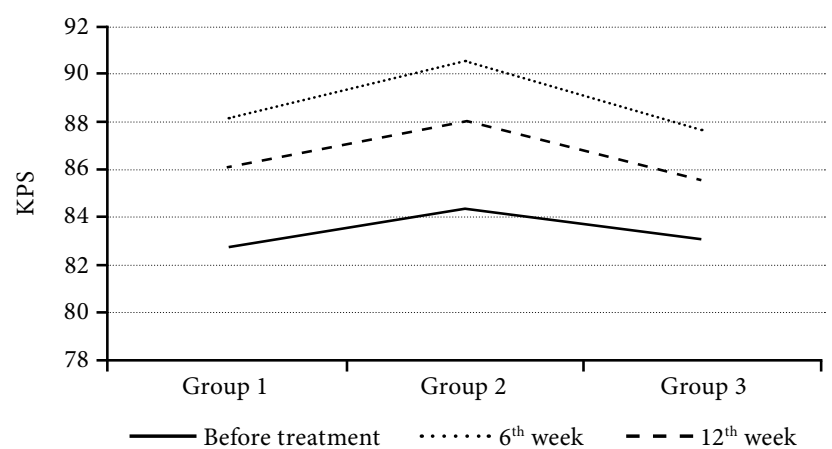

Figure 4. The changes in Kujala Patellofemoral Scale (KPS) scores at week 6 and week 12 . 
Table 1. Age, weight, height, Body Mass Index values of the patients

\begin{tabular}{|c|c|c|c|c|c|c|c|c|c|c|c|c|c|c|}
\hline & \multicolumn{3}{|c|}{ All patients $(\mathrm{n}=75)^{\star}$} & \multicolumn{3}{|c|}{ Group $1(n=25)^{\star}$} & \multicolumn{3}{|c|}{ Group $2(\mathrm{n}=25)^{*}$} & \multicolumn{3}{|c|}{ Group $3(n=25)^{\star}$} & \multirow[b]{2}{*}{$\mathrm{F}$} & \multirow[b]{2}{*}{$p$} \\
\hline & $\mathrm{n}$ & $\%$ & Mean \pm SD & $\mathrm{n}$ & $\%$ & Mean \pm SD & $\mathrm{n}$ & $\%$ & Mean \pm SD & $\mathrm{n}$ & $\%$ & Mean \pm SD & & \\
\hline Age (year) & & & $33.8 \pm 7.9$ & & & $36.0 \pm 8.0$ & & & $31.7 \pm 8.5$ & & & $33.8 \pm 6.7$ & 1.860 & $0.163 \#$ \\
\hline BMI & & & $25.1 \pm 3.4$ & & & $25.6 \pm 2.6$ & & & $24.2 \pm 3.3$ & & & $25.2 \pm 3.9$ & 1.947 & $0.150 \#$ \\
\hline Height & & & $1.7 \pm 0.1$ & & & $1.7 \pm 0.1$ & & & $1.7 \pm 0.1$ & & & $1.7 \pm 0.1$ & 1.662 & $0.197 \#$ \\
\hline Weight & & & $71.5 \pm 13.7$ & & & $70.0 \pm 10.7$ & & & $69.0 \pm 13.5$ & & & $75.4 \pm 16.0$ & 1.650 & $0.199 \#$ \\
\hline Gender & & & & & & & & & & & & & $\chi^{2}$ & \\
\hline Female & 23 & 53.5 & & 11 & 68.7 & & 7 & 50 & & 5 & 38.5 & & 2.746 & $0.253^{*}$ \\
\hline Male & 20 & 46.5 & & 5 & 31.3 & & 7 & 50 & & 8 & 61.5 & & & \\
\hline
\end{tabular}

* The number of knees; SD: Standard deviation; \# One-way ANOVA; ${ }^{*}$ Pearson’s chi-square test; BMI: Body mass index.

"Y" tapes were applied with no tension by driving the upper tail of the tape toward the upper patella, and the lower tail of the tape toward the lower patella (Figure 2).

\section{Statistical analysis}

The Cohen's d effect size was used to obtain the power of study. According to the power analysis, 66 patients were required $(\mathrm{p}=0.05$, power $=0.80$, effect size $=0.40$ ). Statistical analysis was performed using the PASW version 19.0 software (SPSS Inc., Chicago, IL, USA). Continuous variables were expressed in mean \pm standard deviation (SD), and median (min-max) values. Categorical variables were expressed in frequency and percentage. Normality of the continuous variables was analyzed with the Shapiro-Wilk test. One-way analysis of variance (ANOVA) was performed for the inter-group comparisons of the normally distributed variables, while the Kruskal-Wallis test was used for the inter-group comparisons of the abnormally distributed variables. For non-parametric data, the Friedman test was used to evaluate the significant difference in the VAS and KPS scores at the predefined time points. The Nemenyi test was used for pairwise comparisons. The Pearson's chi-square test was used to compare categorical variables among the groups. A $p$ value of less than 0.5 was considered statistically significant.

\section{RESULTS}

A total of 60 patients who were admitted to the Department of Physical Medicine and Rehabilitation for the anterior knee pain and diagnosed with PFPS were screened and the study included a total of 43 patients (75 knees).

Of the patients, $53.5 \%$ were females and $46.5 \%$ were males. Demographic characteristics are shown in Table 1. There were no statistically significant differences between the three groups in terms of age, sex, height, weight, and Body Mass Index ( $p>0.05$, for all).

Duration of pain was found to be 12 (range, 6 to 72) months for Group 1, seven (range, 6 to 12) months for Group 2, and eight (range, 6 to 24) months for Group 3. Pain duration of Group 1 was found to be longer than Group 2 and Group 3 ( $p=0.003$ and $\mathrm{p}=0.008$, respectively). However, there was no significant difference in the pain duration between Group 2 and Group 3 ( $\mathrm{p}=1.000)$.

Table 2. Visual Analog Scale and Kujala Patellofemoral Scale scores of the groups before the treatment and at week 6 and week 12

\begin{tabular}{|c|c|c|c|c|c|c|c|c|}
\hline & \multicolumn{2}{|c|}{ Group 1} & \multicolumn{2}{|c|}{ Group 2} & \multicolumn{2}{|c|}{ Group 3} & \multirow[b]{2}{*}{$\chi^{2}$} & \multirow[b]{2}{*}{$p$} \\
\hline & Median & Min-Max & Median & Min-Max & Median & Min-Max & & \\
\hline $\begin{array}{l}\text { Visual Analog Scale } \\
\quad(0-100 \mathrm{~mm})\end{array}$ & & & & & & & 0.452 & \\
\hline Before treatment & 40 & $20-70$ & 50 & $30-80$ & 50 & $20-80$ & & 0.726 \\
\hline $6^{\text {th }}$ week & 30 & $0-50$ & 20 & $0-40$ & 20 & $0-40$ & & - \\
\hline $12^{\text {th }}$ week & 40 & $0-60$ & 30 & $0-60$ & 30 & $10-50$ & & - \\
\hline $\begin{array}{l}\text { Kujala Patellofemoral Scale } \\
\quad(0-100)\end{array}$ & & & & & & & 0.701 & \\
\hline Before treatment & 84 & $70-91$ & 85 & $72-96$ & 84 & $67-91$ & & 0.587 \\
\hline $6^{\text {th }}$ week & 87 & $74-100$ & 89 & $81-100$ & 87 & $82-94$ & & - \\
\hline $12^{\text {th }}$ week & 87 & $74-96$ & 88 & $76-98$ & 86 & $76-92$ & & - \\
\hline
\end{tabular}


Table 3. Comparison of change (\%) of week 6 and week 12 in Visual Analog Scale and Kujala Patellofemoral Scale scores among groups

\begin{tabular}{|c|c|c|c|c|c|c|c|c|}
\hline & \multicolumn{2}{|c|}{ Group 1} & \multicolumn{2}{|c|}{ Group 2} & \multicolumn{2}{|c|}{ Group 3} & \multirow[b]{2}{*}{$\chi^{2}$} & \multirow[b]{2}{*}{$p$} \\
\hline & Median & Min-Max & Median & Min-Max & Median & Min-Max & & \\
\hline \multicolumn{9}{|c|}{$\begin{array}{l}\text { Visual Analog Scale } \\
\quad(0-100 \mathrm{~mm})\end{array}$} \\
\hline Change 1 & -50.0 & $-1--0.17$ & -50.0 & $-1--0.33$ & -50.0 & $-1--0.20$ & 3.448 & 0.178 \\
\hline Change 2 & -20.0 & $-1-0.25$ & -33.3 & $-1-0$ & -28.6 & $-0.5-0$ & 2.373 & 0.305 \\
\hline \multicolumn{9}{|c|}{$\begin{array}{l}\text { Kujala Patellofemoral Scale } \\
\quad(0-100)\end{array}$} \\
\hline Change 1 & 5.71 & $0.01-0.18$ & 5.95 & $0.01-0.23$ & 4.44 & $0-0.25$ & 1.086 & 0.581 \\
\hline Change 2 & 3.49 & $0-0.18$ & 2.47 & $0-0.21$ & 2.38 & $0-0.13$ & 0.230 & 0.891 \\
\hline
\end{tabular}

Min: Minimum; Max: Maximum; Change 1: Before treatment $-6^{\text {th }}$ week; Change 2: Before treatment $-12^{\text {th }}$ week.

Table 4. Changes in the Visual Analog Scale and Kujala Patellofemoral Scale scores of the groups at the end of week 6 and week 12

\begin{tabular}{|c|c|c|c|c|c|c|}
\hline & \multicolumn{2}{|c|}{ Group 1} & \multicolumn{2}{|c|}{ Group 2} & \multicolumn{2}{|c|}{ Group 3} \\
\hline & Median & Min-Max & Median & Min-Max & Median & Min-Max \\
\hline \multicolumn{7}{|l|}{$\begin{array}{l}\text { Visual Analog Scale } \\
\qquad(0-100 \mathrm{~mm})\end{array}$} \\
\hline Before treatment & 40 & $20-70$ & 50 & $30-80$ & 50 & $20-80$ \\
\hline $6^{\text {th }}$ week & 30 & $0-50$ & 20 & $0-40$ & 20 & $0-40$ \\
\hline $12^{\text {th }}$ week & 40 & $0-60$ & 30 & $0-60$ & 30 & $10-50$ \\
\hline$\chi^{2}$ & \multicolumn{2}{|c|}{43.934} & \multicolumn{2}{|c|}{44.273} & \multicolumn{2}{|c|}{45.916} \\
\hline$p$ & \multicolumn{2}{|c|}{$\mathrm{p}<0.001$} & \multicolumn{2}{|c|}{$\mathrm{p}<0.001$} & \multicolumn{2}{|c|}{$\mathrm{p}<0.001$} \\
\hline \multicolumn{7}{|c|}{$\begin{array}{l}\text { Kujala Patellofemoral Scale } \\
\qquad(0-100)\end{array}$} \\
\hline Before treatment & 84 & $70-91$ & 85 & $72-96$ & 84 & $67-91$ \\
\hline $6^{\text {th }}$ week & 87 & $74-100$ & 89 & $81-100$ & 87 & $82-94$ \\
\hline $12^{\text {th }}$ week & 87 & 74-96 & 88 & 76-98 & 86 & 76-92 \\
\hline$\chi^{2}$ & \multicolumn{2}{|c|}{39.609} & \multicolumn{2}{|c|}{42.944} & \multicolumn{2}{|c|}{42.000} \\
\hline$p$ & \multicolumn{2}{|c|}{$\mathrm{p}<0.001$} & \multicolumn{2}{|c|}{$\mathrm{p}<0.001$} & \multicolumn{2}{|c|}{$\mathrm{p}<0.001$} \\
\hline
\end{tabular}

Min: Minimum; Max: Maximum; Change 1: Before treatment - $6^{\text {th }}$ week; Change 2: Before treatment $-\chi^{2}: 12^{\text {th }}$ week; Chi-square.

There was no statistically significant difference in the VAS and KPS values before the treatment of the groups among the groups $(\mathrm{p}=0.726$ and $\mathrm{p}=0.587$, respectively) (Table 2). In addition, no statistically significant changes were found in the VAS and KPS scores of the groups at Week 6 and 12 (Table 3).

According to the Friedman test results, there was a statistically significant difference in the VAS scores of each group at different time points $(\mathrm{p}=0.001, \mathrm{p}=0.001$, and $\mathrm{p}=0.001$, respectively) (Figure 3 ). Similar to the VAS scores, there was a statistically significant difference in the KPS scores of each group at different time points $(\mathrm{p}=0.001, \mathrm{p}=0.001$, and $\mathrm{p}=0.001$, respectively). The mean changes in the VAS and KPS scores are shown in Table 4, Figure 4.

\section{DISCUSSION}

Musculus vastus medialis obliquus contracts earlier than $M$. vastus lateralis during the extension motion of the knee. Neptune et al. ${ }^{[25]}$ reported that delay in the VMO timing caused an increase in the lateral PFE load. In the light of these data, we considered that facilitating the VMO muscle would both reduce the pain and improve the activities. Therefore, we applied kinesiotaping on the VMO muscle in our study. We also included exercises regarding strengthening this muscle in the exercise program. We found significant improvements for all the groups in both pain scores and in the KPS, in which daily activities such as going down and up the stairs and squatting were assessed. We planned this study based on the hypothesis that the tape application alongside with the exercises would create a better response; however, we were unable to show any statistically significant differences among the groups.

Pain is the main symptom in PFPS. A histological study has demonstrated that patellar retinaculum, patellar, and quadriceps tendons, synovium, fat pad, 
and subchondral bone contain nerve fibers which may cause pain in PFPS. ${ }^{[4]}$ It has been shown in many studies that conservative treatment methods used for PFPS treatment are effective in reducing pain. ${ }^{[8,26,27]}$

Kinesiotaping is also a frequently used method for PFPS treatment in recent years. Studies carried out by Campolo et al. ${ }^{[28]}$ Lan et al., ${ }^{[29]}$ and Akbaş et al. ${ }^{[18]}$ showed that kinesiotaping for PFPS reduced pain. Freedman et al. ${ }^{[30]}$ also reported that kinesiotaping on the patients having PFPS reduced pain and increased the jumping distance on one foot. Kuru et al. ${ }^{[21]}$ studied the effectiveness of the electrical stimulation and kinesiotaping onto the VMO for PFPS. The authors observed decrease in the pain and improvement in the KPS for both the kinesiotaping group and the electrical stimulation group after a six weeks long treatment. In another study, it was reported that kinesiotaping by pain control was able to allow the patients to do quadriceps exercises without any pain. ${ }^{[27]}$ In our study, pain was statistically significantly reduced in all three groups and this improvement also sustained at week 12 .

The KPS has been developed to assess the subjective symptoms and the functional limitations in the patellofemoral disorders. ${ }^{[23]}$ Patellofemoral pain syndrome limites the activities through which patellofemoral joint is loaded (i.e., walking, running, squatting). These activities are assessed in the KPS, which is a specific scale for PFPS including 13 questions in different categories related to different levels of the knee functions. Watson ${ }^{[31]}$ found the KPS highly reliable as well as steady response to the clinical changes in his study including 30 patients. ${ }^{[31]}$ Kuru et al. ${ }^{[24]}$ carried out a study on the validity and reliability of the KPS in PFPS for Turkish and internal consistency of the Kujala patellofemoral scoring translated into Turkish was found to be adequate and it was shown to be highly reliable with the test-retest method. We used VAS for the assessment of the pain, and KPS for the assessment of the daily living activities.

The facilitation of quadriceps muscle has been the main objective in almost all the studies on the effectiveness of the kinesiotaping for PFPS, and patellar correction has been made in some of those studies. The variety of methods has been used for the treatments on quadriceps muscle including kinesiotaping. ${ }^{[18,19,21,28,32,33]}$ Kinesiotaping application, apart from the quadriceps muscle, has also been performed on gluteal muscles, femur and iliotibial band and their effects on PFPS treatment has been investigated. In a study carried out by Miller et al., ${ }^{[34]}$ the effectiveness of lateral gluteal kinesiotaping and lumbopelvic manipulation in PFPS treatment was assessed. In the aforementioned study, in which 18 patients were involved, the patients were randomized into three groups (kinesiotaping, manipulation, and control groups). The patients were assessed via the Y-balance test, motion range of the knee joint during squatting, and the Lower Extremity Functional Scale. Both lateral gluteal kinesiotaping and the lumbopelvic manipulation were found to be effective and no statistically significant differences were found between them. In a study, Song et al. ${ }^{[35]}$ found that femoral rotational taping had an effect on pain, lower extremity motion and muscle activity for the patients with PFPS. The fact that taping applications used in previous studies are not standardized, leading to insufficient evidences to show the effects in the systematic reviews. ${ }^{[3,8,27]}$

It is one of the argumentative topics in the literature that sham taping applications may also be effective in kinesiotaping studies. ${ }^{[20,36]}$ In a study carried out by Christou, ${ }^{[16]}$ effectiveness of placebo taping and effectiveness of kinesiotaping on 15 patients having PFPS and 20 healthy individuals were compared. ${ }^{[16]}$ While both placebo taping and kinesiotaping were found to have reduced the pain for the patients having PFPS, it was also found out that vastus medialis EMG activity increased without an increase in the muscle strength and vastus lateralis activity decreased. The authors, therefore, suggested that the effect might have been present through sensory change on the patellofemoral ligament rather than medialized patella. There are studies supporting this view and suggesting that kinesiotaping becomes effective by increasing the proprioceptive entry or neuromuscular control. ${ }^{[27,37]}$ In the case of our study, applying sham taping along the long axis of the VMO muscle might have had a nociceptive activator effect, although the length of the tape was short. Thus, taking this nociceptive effect into account in determining the sham kinesiotaping application may be useful for the future researches.

Total numbers of the patients in the studies on the effects of the patellar taping application have been often low as in our study. Involving both knees for some patients may have had an effect on the results of our study, and this may be accepted as the blind side of our study. Although the effect of treatment on physical activity was compared using the KPS, the physical activity levels of the patients were not questioned in detail. This can be considered as another weakness of this study. Besides, inclusion of all the patients in the exercise program may have resulted in the lack of difference among the groups, as the 
treatment methods which affect PFPS are proven are particularly the quadriceps exercises. It has been most particularly emphasized that vastus medialis must be strengthen and supported in the treatment of the disease. ${ }^{[4]}$ In a systematic review by Bolgla and Boling, ${ }^{[8]}$ exercise was found to be the most effective method in the conservative treatment of PFPS. It was also reported that other applications such as patellar taping, patellar brace, knee brace and foot orthotics were singly less effective, compared to the exercise. ${ }^{[8]}$

In conclusion, the addition of the kinesiotaping application to the exercise treatment for PFPS seems to be ineffective on pain control and improved daily life activities. However, further large-scale studies using standardized taping methods are needed to establish a definite conclusion.

\section{Declaration of conflicting interests}

The authors declared no conflicts of interest with respect to the authorship and/or publication of this article.

\section{Funding}

The authors received no financial support for the research and/or authorship of this article.

\section{REFERENCES}

1. Aglietti P, Buzzi R, Insall J. Disorders of the patellofemoral joint. In: Insall J, editor. Surgery of the knee. New York: Churchill Livingstone Inc; 1993. p. 241-385.

2. Fulkerson JA, Buuck AA. Patellofemoral joint anatomy. In: Fulkerson JA, editor. Disorders of the patellofemoral joint. Baskı yeri: Lippincott Williams \& Wilkins; 2004. p. 1-24.

3. Callaghan MJ, Selfe J. Patellar taping for patellofemoral pain syndrome in adults. Cochrane Database Syst Rev 2012;4:CD006717.

4. LaBella C. Patellofemoral pain syndrome: evaluation and treatment. Prim Care 2004;31:977-1003.

5. Donell ST, Joseph G, Hing CB, Marshall TJ. Modified Dejour trochleoplasty for severe dysplasia: operative technique and early clinical results. Knee 2006;13:266-73.

6. Gerbino PG, Griffin ED, d'Hemecourt PA. Patellofemoral pain syndrome: evaluation of location and intensity of pain. Clin J Pain 2006;22:154-9.

7. Earl JE, Vetter CS. Patellofemoral pain. Phys Med Rehabil Clin N Am 2007;18:439-58.

8. Bolgla LA, Boling MC. An update for the conservative management of patellofemoral pain syndrome: a systematic review of the literature from 2000 to 2010. Int J Sports Phys Ther 2011;6:112-25.

9. van der Heijden RA, Lankhorst NE, van Linschoten R, Bierma-Zeinstra SM, van Middelkoop M. Exercise for treating patellofemoral pain syndrome. Cochrane Database Syst Rev 2015;1:CD010387.

10. Celiker R, Guven Z, Aydoğ T, Bagis S, Atalay A, Caglar Yagci, et al. The kinesiologic taping technique and its applications. Turk J Phys Med Rehab 2011;57:225-35.
11. Chen CY, Lou MY. Effects of the application of Kinesio-tape and traditional tape on motor perception. . Br J Sports Med 2008;42:513-40.

12. Firth BL, Dingley P, Davies ER, Lewis JS, Alexander CM. The effect of kinesiotape on function, pain, and motoneuronal excitability in healthy people and people with Achilles tendinopathy. Clin J Sport Med 2010;20:416-21.

13. Halseth T, McChesney JW, Debeliso M, Vaughn R, Lien J. The effects of kinesio ${ }^{\mathrm{Tm}}$ taping on proprioception at the ankle. J Sports Sci Med 2004;3:1-7.

14. Karadag-Saygi E, Cubukcu-Aydoseli K, Kablan N, Ofluoglu D. The role of kinesiotaping combined with botulinum toxin to reduce plantar flexors spasticity after stroke. Top Stroke Rehabil 2010;17:318-22.

15. Kase KR, Wallis J, Kase T. Clinical therapeutic application of the kinesiotaping method. Tokyo: Ken Ikai Co Ltd; 2003.

16. Christou EA. Patellar taping increases vastus medialis oblique activity in the presence of patellofemoral pain. J Electromyogr Kinesiol 2004;14:495-504.

17. Słupik A, Dwornik M, Białoszewski D, Zych E. Effect of Kinesio Taping on bioelectrical activity of vastus medialis muscle. Preliminary report. Ortop Traumatol Rehabil 2007;9:644-51.

18. Akbaş E, Atay AO, Yüksel I. The effects of additional kinesio taping over exercise in the treatment of patellofemoral pain syndrome. Acta Orthop Traumatol Turc 2011;45:335-41.

19. Bayrakci V, Akyüz A, Önal S, Güder Usgu G, Dogan G, Teker B. Patellofemoral ağrı sendromunda kinezyo ve McConnell patellar bantlama tekniklerinin performans üzerine anlık etkilerinin karşılaştırılması. Fizyoterapi ve Rehabilitasyon 2008;19:104-9.

20. Whittingham M, Palmer S, Macmillan F. Effects of taping on pain and function in patellofemoral pain syndrome: a randomized controlled trial. J Orthop Sports Phys Ther 2004;34:504-10.

21. Kuru T, Yalıman A, Dereli EE. Comparison of efficiency of Kinesio taping and electrical stimulation in patients with patellofemoral pain syndrome. Acta Orthop Traumatol Turc 2012;46:385-92.

22. Chesworth BM, Culham E, Tata GE, Peat M. Validation of outcome measures in patients with patellofemoral syndrome. J Orthop Sports Phys Ther 1989;10:302-8.

23. Kujala UM, Jaakkola LH, Koskinen SK, Taimela S, Hurme M, Nelimarkka O. Scoring of patellofemoral disorders. Arthroscopy 1993;9:159-63.

24. Kuru T, Dereli EE, Yaliman A. Validity of the Turkish version of the Kujala patellofemoral score in patellofemoral pain syndrome. Acta Orthop Traumatol Turc 2010;44:152-6.

25. Neptune RR, Wright IC, van den Bogert AJ. The influence of orthotic devices and vastus medialis strength and timing on patellofemoral loads during running. Clin Biomech (Bristol, Avon) 2000;15:611-8.

26. Al-Hakim W, Jaiswal PK, Khan W, Johnstone D. The nonoperative treatment of anterior knee pain. Open Orthop J 2012;6:320-6.

27. Aminaka N, Gribble PA. A systematic review of the effects of therapeutic taping on patellofemoral pain syndrome. J Athl Train 2005;40:341-51. 
28. Campolo M, Babu J, Dmochowska K, Scariah S, Varughese J. A comparison of two taping techniques (kinesio and mcconnell) and their effect on anterior knee pain during functional activities. Int J Sports Phys Ther 2013;8:105-10.

29. Lan TY, Lin WP, Jiang CC, Chiang H. Immediate effect and predictors of effectiveness of taping for patellofemoral pain syndrome: a prospective cohort study. Am J Sports Med 2010;38:1626-30.

30. Freedman SR, Brody LT, Rosenthal M, Wise JC. Short-term effects of patellar kinesio taping on pain and hop function in patients with patellofemoral pain syndrome. Sports Health 2014;6:294-300.

31. Watson CJ, Propps M, Ratner J, Zeigler DL, Horton P, Smith SS. Reliability and responsiveness of the lower extremity functional scale and the anterior knee pain scale in patients with anterior knee pain. J Orthop Sports Phys Ther 2005;35:136-46.

32. Chang WD, Chen FC, Lee CL, Lin HY, Lai PT. Effects of Kinesio Taping versus McConnell Taping for Patellofemoral Pain Syndrome: A Systematic Review and Meta-Analysis.
Evid Based Complement Alternat Med 2015;2015:471208.

33. Howe A, Campbell A, Ng L, Hall T, Hopper D. Effects of two different knee tape procedures on lower-limb kinematics and kinetics in recreational runners. Scand J Med Sci Sports 2015;25:517-24.

34. Miller J, Westrick R, Diebal A, Marks C, Gerber JP. Immediate effects of lumbopelvic manipulation and lateral gluteal kinesio taping on unilateral patellofemoral pain syndrome: a pilot study. Sports Health 2013;5:214-9.

35. Song CY, Huang HY, Chen SC, Lin JJ, Chang AH. Effects of femoral rotational taping on pain, lower extremity kinematics, and muscle activation in female patients with patellofemoral pain. J Sci Med Sport 2015;18:388-93.

36. Crossley K, Bennell K, Green S, Cowan S, McConnell J. Physical therapy for patellofemoral pain: a randomized, double-blinded, placebo-controlled trial. Am J Sports Med 2002;30:857-65.

37. Chang HY, Chou KY, Lin JJ, Lin CF, Wang CH. Immediate effect of forearm Kinesio taping on maximal grip strength and force sense in healthy collegiate athletes. Phys Ther Sport 2010;11:122-7. 